\title{
Impact of Mix Preparation on Strength and Workability of High Strength Self-Consolidated Lightweight Concrete
}

\author{
Sharef Farrag ${ }^{1}$, Sherif Yehia ${ }^{2}$ \\ ${ }^{I}$ (Graduate Research Assistant, Department of Civil Engineering, American University of Sharjah, \\ United Arab Emirates) \\ ${ }_{2}^{2}$ (Associate Professor, Department of Civil Engineering, American University of Sharjah, United Arab \\ Emirates)
}

\begin{abstract}
This paper presents an assessment of the challenges faced and lessons learned during the transfer from the laboratory development to mass production for field implementation of High-strength Self-consolidated Lightweight Concrete (HSSCLWC). The evaluation included mechanical properties, workability, Rapid Chloride Penetration testing, and Scanning Electron Microscope images. Due to the difference in material performance depicted by the difference in microstructural features and durability aspects, structural performance of elements casted will not necessarily follow predicted behavior although they have the same compressive strength. Moreover, although the $\lambda$ factor is introduced to realize the reduction of tensile properties of lightweight concrete compared to normal weight concrete, it was found that due to the difference in handling and mix preparation, the $\lambda$ factorbecomes more inexact at capturing actual performance.
\end{abstract}

Keywords:Self-consolidating concrete, SCC, Lightweight aggregate, Field Implementation

\section{Introduction}

Concerns aboutthe depletionof natural resources and increasing demand on replacing normal weight aggregate in concrete production for sustainable development, especially in marine construction, have led to the adoption of several alternatives. Such alternatives include recycled aggregates as well as, more common, lightweight aggregates. Lightweight aggregate concrete is a viable substitute to normal weight concrete, for it enhances many of the concrete durability aspects, as well as reducing the dead load[1].Many research efforts prove the superiority of lightweight aggregate concrete in freeze and thaw cycles over normal weight concrete, showing less reduction of concrete strength and higher deformation resistance due to the lower restraint $[2,3]$. Moreover, it helps enhance the chloride penetration resistance of concrete due to its cellular structure that traps chlorides ions in its pores [4,5]. Lightweight aggregates (LWA) mainly are classified into natural aggregates such as pumice and scoria, and manufactured aggregates such as sintered pulverized fuel ash and lightweight expanded clay. Table 1 provides highlights about common lightweight aggregates for structural applications and their properties.

Table 1. Common lightweight aggregates for structural application $[2,3,5]$

\begin{tabular}{|l|l|l|l|l|}
\hline $\begin{array}{l}\text { Lightweight } \\
\text { aggregate }\end{array}$ & Common application & $\begin{array}{l}\text { Bulk density } \\
\left(\mathbf{k g} / \mathbf{m}^{\mathbf{3}}\right)\end{array}$ & $\begin{array}{l}\text { Specific gravity } \\
\text { factor }\end{array}$ & $\begin{array}{l}\text { Absorption } \\
\mathbf{( \% )}\end{array}$ \\
\hline Pumice & reinforced concrete slabs & $500-800$ & $1.10-1.40$ & $15-60$ \\
\hline Foamed Slag & $\begin{array}{l}\text { suitable for large production } \\
\text { of reinforced concrete } \\
\text { applications }\end{array}$ & $\begin{array}{l}900-\text { fine } \\
650-\text { coarse }\end{array}$ & 1.1 & $10-50$ \\
\hline Expanded Clays & $\begin{array}{l}\text { capable of achieving high } \\
\text { strength for prestressed } \\
\text { concrete }\end{array}$ & $650-900$ & $<1(\sim 0.7)$ & $10-35$ \\
\hline $\begin{array}{l}\text { Sintered Pulverized- } \\
\text { fuel ash aggregate }\end{array}$ & $\begin{array}{l}\text { variety of structural } \\
\text { applications and is being } \\
\text { marketed under the trade } \\
\text { name LYTAG }\end{array}$ & $\begin{array}{l}1050-\text { fine } \\
800-\text { coarse }\end{array}$ & $1.15-1.30$ & $15-35$ \\
\hline
\end{tabular}

Physical properties of lightweight aggregates play an important role in the production of lightweight concrete. Such properties include specific gravity factor, porosity, and shape. These factors require special preparation of the aggregates such as sieving and pre-wetting, which can critically affect the final product. Moreover, high absorption of lightweight aggregates can cause alteration of the effective mixing water, hence alteration in water-to-binder ratio $(w / b)$. Many research efforts are focused on the evaluation of lightweight aggregate properties to improve the mechanical and durability related properties of lightweight concrete [5-8].

On the other hand, field applications of concrete utilizing LWA for actual construction is a crucial factor in the development of lightweight concrete. Aggregate handling and mix preparation procedures of 
lightweight concrete can differ between laboratorial applications and ready mix producers, because of the contrast of available technology and equipment. Differences can include presoaking/pre-wetting techniques, storage methods, availability of materials, and special aggregate processing (i.e. special gradation requirements). ACI-318 introduced the $\lambda$ modifier to the mechanical properties equations, as a reduction factor relative to normal weight concrete. This factor affects many structural design aspects including flexural design (cracking moment and transition stage) through modulus of rupture, combined shear stresses, deep beams, prestressed/pretensioned concrete, and development length of reinforcement. The modifier $\lambda$ is based on laboratory testing of tensile strength of lightweight concrete and comparing it with that of normal weight concrete. Nevertheless, there is no evidence that the $\lambda$ value used for design accurately captures the reduced properties of constructed structural elements. In addition, changes occurring due to differences in mix preparation can even widen the gap of uncertainty. Moreover, problems related to cast-in-place LWC are of great importance, since typical mix remedial techniques of flawed normal weight concrete might not be the best solution for lightweight concrete.

Self-compacting Concrete (SCC) can speed up construction and make it easier to pump concrete, especially in tall building. Thus, its application is ever increasing in cast-in-place structures, as well as precast concrete application $[9,10]$.Nevertheless, the implications of applying SCC utilizing lightweight aggregates in real life construction is not addressed thoroughly. In this paper, evaluation of a field implementation of high strength self-consolidated lightweight concrete is presented and lessons learned from the transition of the developed mix are discussed. The effect of differences between lab and field practices on strength and durability of lightweight concrete were assessed.

\section{Background}

There are many marine structures and bridges that were constructed using LWC in the USA, benefiting from dead load reduction while maintainingcomparablestrengthcapacity. Examplesof structural lightweight aggregate application are presented in Table 2.Nevertheless, problems occurring during casting and their impact on strength and durability of concrete are rarely discussed in the literature[11].Enhanced freeze and thaw resistance, reduced shrinkage [12], higher thermal insulation [13], lower alkali-silica reaction occurrence and damage $[14,15]$, higher chloride diffusion resistance, and lower unit weight are among the desirable advantages reported in the literature. However, there are some limitations accompanied with its application. Higher creep strain accompanied with low elasticity, lower strength compared to normal weight concrete at optimal $\mathrm{w} / \mathrm{b}$ ratio, and high sensitivity to production preparations. Yet overall, LWC is a sustainable alternative to normal weight concrete. The advantages and limitations of lightweight aggregate concrete application arise from the physical properties of lightweight aggregate, as well as pre-mixing procedures. Specific gravity factor, bulk density, absorption, and shape of aggregates are the most important factors in the production/development of lightweight concrete. Table 3 presents a summary of aggregates properties that have an effect on LWC mixing/production. Unlike laboratorial practices in which pre-wetting water is added 30 minutes to the aggregate prior to mixing to accommodate the aggregate's absorption, concrete batching for mass production follows automated materials addition and mixing procedures that are most likely uninterruptable. This can raise a challenge for unequipped batch plants. In addition, in a hot weather region like the GCC area the estimation of ice volume to be added can negatively affect the intended water to cementitious ratio $(\mathrm{w} / \mathrm{cm})$ if not done properly. In turn, this can affect concrete strength and durability. Moreover, the unavailability of required materials for a mix might impose adjustments to the mix design. Such transitional measures should be accounted for, in order to manage expected results of a mix. Consequently, self-consolidated lightweight concrete is one of the novel alternatives for conventional concrete, since it combines dead load reduction features, in addition to flowability to overcome steel congestion. This can facilitate design requirements and provide more options for structural design. Mechanical properties, durability aspects, and rheological features of self-consolidated concrete have been thoroughly evaluated in the literature [16-22]. Furthermore, efforts to introduce LWA to SCC in order to develop Self-Consolidating Lightweight Concrete (SCLWC) were investigated [23-25]. Yet, all efforts report laboratory preparations of SCLWC.

Table 2. Examples of structural lightweight concrete application[26, 27]

\begin{tabular}{|l|c|l|}
\hline Structure & Year Constructed & Lightweight members \\
\hline $\begin{array}{l}\text { Cooper River Bridge, South } \\
\text { Carolina }\end{array}$ & 1992 & $\begin{array}{l}\text { Cast-in-place deck over precast } \\
\text { lightweight panels and barriers }\end{array}$ \\
\hline Heart of America Bridge, Missouri & 1985 & $\begin{array}{l}\text { Pre-cast deck panels, and cast-in-place } \\
\text { LWC deck }\end{array}$ \\
\hline Kingston Bridge, London & 1997 & Pre-cast arches \\
\hline $\begin{array}{l}\text { Terminal 3 Concourse in Dubai } \\
\text { International Airport, Dubai }\end{array}$ & 2010 & Concrete Floor \\
\hline
\end{tabular}


Table 3. Effect of various aggregate physical properties on lightweight concrete

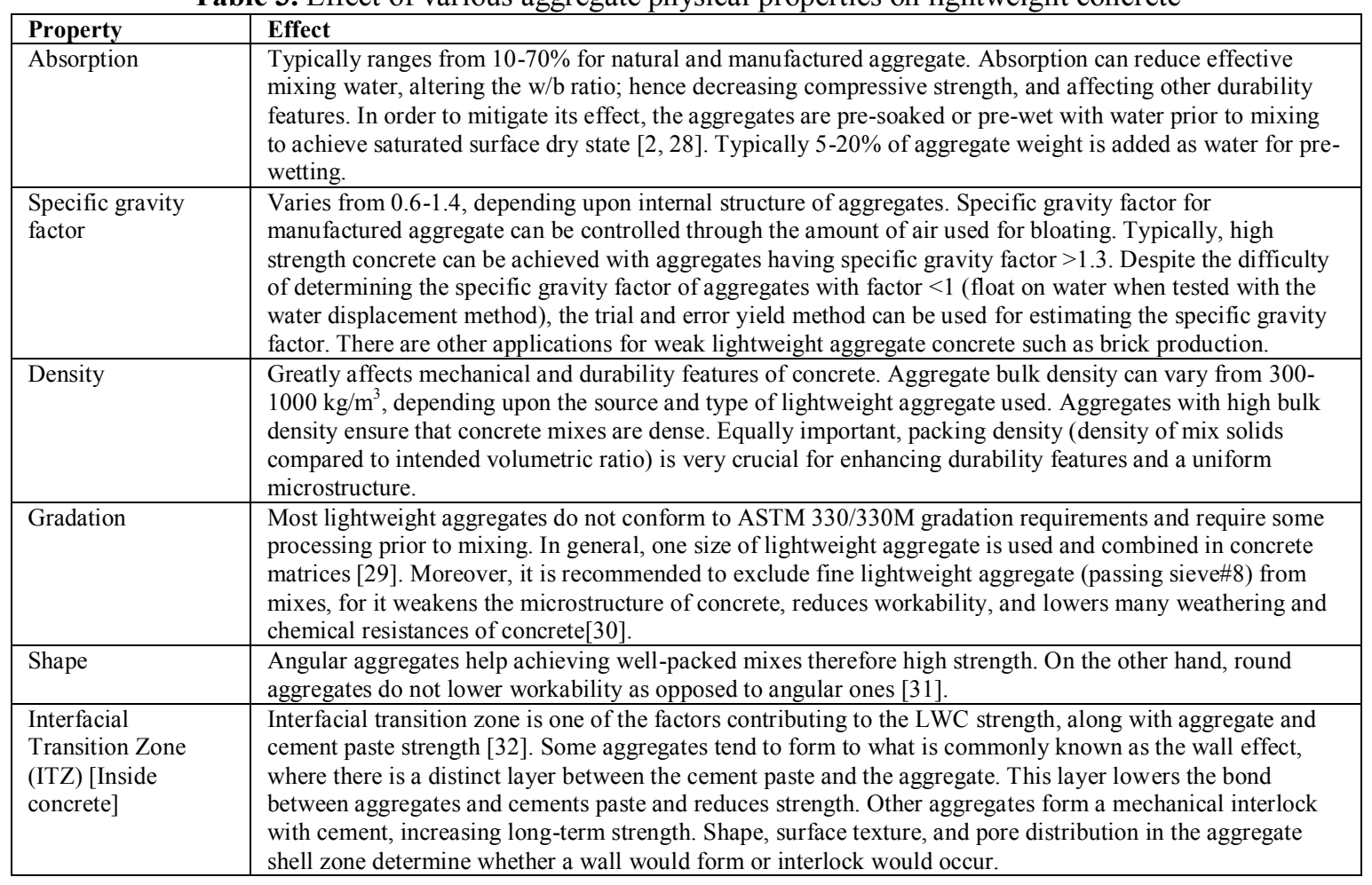

A recent study was carried out to quantify the impact of the lab-field transition on the properties of structural lightweight aggregate concrete(SLWAC, in which normal and high strength lightweight concrete were evaluated [11]. It was shown that difference in mixing procedures and aggregate handling had low impact on the mechanical properties and unit weight in general. Nevertheless, there was a significant increase in chloride ion penetration. Such differences in mixing and preparation are expected to adversely affect self-consolidating high strength lightweight concrete (HSSCLWC) in an amplified manner. In addition, codes and standard procedures are aimed towards mix design and structural design requirements of concrete. Table 4 highlights the main excerpts from ACI 318 building code regarding design requirements, which shows that mechanical properties of SLWAC, centralized around $f_{c}$, are more emphasized. However, no or less attention is paid to concrete production/casting and their potential adverse effect on durability, which can lead to unhealthy concrete and deterioration. Thus, field application of HSSCLWC and in-situ experiences are yet to be investigated, in order to overcome the superimposed repercussions of employing concrete that is both lightweight and flowable. Each of these requirements requires special attention at the development stage starting from aggregate evaluation and selection, to mix proportioning. Therefore, this paper presents the field implantation of a lab prepared mix and a cast-in place mix, reporting the experience and lessons learned from the lab-field transition and observed effects on strength and durability i.e. chloride penetration.

\section{Experimental Investigation}

Application of lightweight concrete (LWC) is not a common practice in the GCC area, and there is little experience with cast-in-place LWC. A concrete batch plant agreed to mix and deliver $2 \mathrm{~m}^{3}$ of LWC to the casting location. The objective was to produce a high strength self-consolidated lightweight concrete mix. The experimental investigation was carried out in Two stages I) Lab Development Stage (Mix \#1), and II) Field Application Stage (Mix \#2). The results of the two stages are presented in the following subsections.

\subsection{Materials:}

The coarse lightweight aggregates used in all stages were sintered pulverized-fuel ash aggregates commonly known as LYTAG with a specific gravity factor $\sim 1.34$ and a bulk density of $790 \mathrm{~kg} / \mathrm{m}^{3}$. The aggregates have 30-minutes absorption of $15.7 \%$ and 24 -hours absorption of $30.1 \%$. Aggregate with size of 4-8 $\mathrm{mm}$ were used as-received, and its gradation is shown in Fig. 1. Fine lightweight aggregates were excluded from all mixes. Fig. 2 shows a sample of the aggregates used in the investigation. 
Table 4. Building code (ACI 318-11) requirements for structural lightweight concrete

\begin{tabular}{|l|l|}
\hline Parameter & ACI 318-11 Requirements \\
\hline Aggregate density & Should be $1120 \mathrm{~kg} / \mathrm{m}^{3}\left(70 \mathrm{lb} . / \mathrm{ft}^{3}\right)$ or less in accordance with ASTM C29. \\
\hline Equilibrium unit weight & $\begin{array}{l}\text { Should be between } 1440-1840 \mathrm{~kg} / \mathrm{m}^{3}\left(90-115 \mathrm{lb} . / \mathrm{ft}^{3}\right) \text { as determined by ASTM C567. One- } \\
\text { way slab thickness is increased based on unit weight if less than } 18401120 \mathrm{~kg} / \mathrm{m}^{3}\left(115 \mathrm{lb} . / \mathrm{ft}^{3}\right)\end{array}$ \\
\hline $\mathrm{w} / \mathrm{cm}$ ratio & $\begin{array}{l}\text { Unspecified due to high absorption of light aggregate and water content is not accurately } \\
\text { known }\end{array}$ \\
\hline $\begin{array}{l}\lambda \text { (Modification factor reflecting } \\
\text { the reduced mechanical properties } \\
\text { of lightweight concrete) }\end{array}$ & $\begin{array}{l}0.75 \text { for all lightweight, } 0.85 \text { for sand-lightweight) or based on volumetric fractions and } \\
\text { linear interpolation when normal weight fine aggregate is replaced with lightweight fine } \\
\text { aggregate. For a blend of normal and lightweight coarse aggregates } \lambda \text { is estimated as splitting } \\
\text { tensile strength/6.7 } \sqrt{\mathrm{f}_{\mathrm{c}}} \text { (in customary units) }\end{array}$ \\
\hline $\begin{array}{l}\text { In addition, durability and design requirements for flexure, shear, development length, prestressed/post-tension, deep beams, and } \\
\text { shear walls are included along with normal weight concrete provisions }\end{array}$ \\
\hline
\end{tabular}

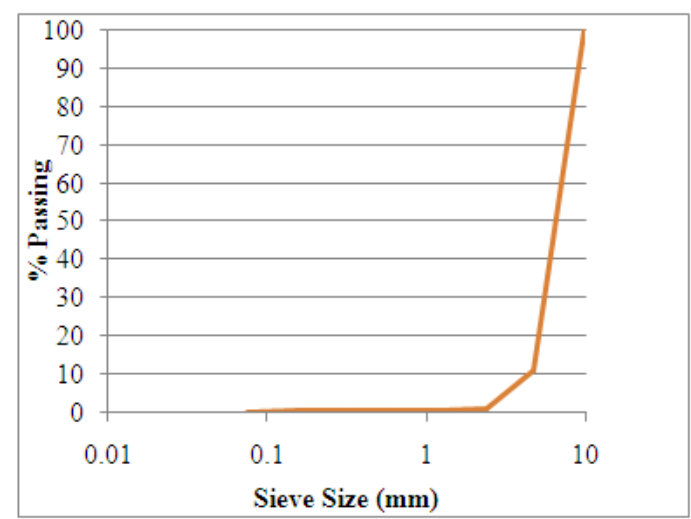

Fig. 1.gradation of as received aggregates

Normal weight fine aggregates were different throughout the progression of the research project, and are presented separately in each stage. Type I cement with specific gravity of 3.15 was used in the laboratory and at the batch plant, in addition to silica fume with specific gravity of 2.2. A commercially available admixture (GLENUIM SKY 504 from BASF) was used to adjust workability levels in stage I and stage II. The mix proportions are summarized in Table5.

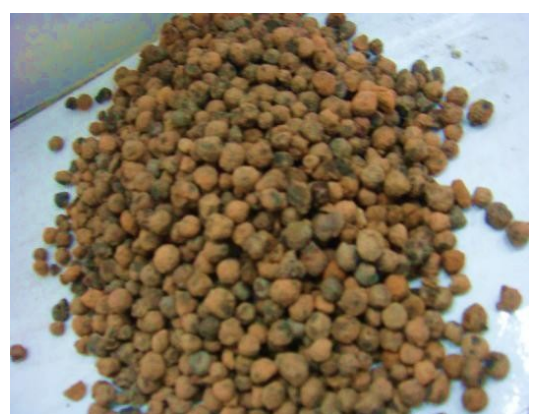

Fig. 2.sintered pulverized-fuel ash aggregates

Table 5. Mix proportions

\begin{tabular}{|l|l|l|}
\hline $\begin{array}{l}\text { Ingredients } \\
\left(\mathbf{k g} / \mathbf{m}^{\mathbf{3}}\right)\end{array}$ & $\begin{array}{l}\text { Mix\#1 } \\
\text { (Stage I) }\end{array}$ & $\begin{array}{l}\text { Mix\#2 } \\
\text { (Stage II) }\end{array}$ \\
\hline w/b & 0.45 & 0.49 \\
\hline $\begin{array}{l}\text { LWA } \\
(\text { LYTAG) }\end{array}$ & $515(0.36)^{*}$ & $450(0.34)$ \\
\hline $\begin{array}{l}\text { Dune } \\
\text { Sand }\end{array}$ & $316(0.12)$ & $440(0.17)$ \\
\hline Washed Sand & 0 & $300(0.12)$ \\
\hline Crushed Sand & $353(0.13)$ & 0 \\
\hline Cement & $405(0.12)$ & $450(0.14)$ \\
\hline Silica Fume & $105(0.05)$ & 0 \\
\hline Water & $230(0.22)$ & $220(0.22)$ \\
\hline Admixture & $5(0.005)$ & $12(0.012)$ \\
\hline Bulk Density & 1929 & 1872 \\
\hline
\end{tabular}

${ }^{*}$ Value in () is volumetric ratio 


\subsection{Project Requirements:}

Four $1.2 \mathrm{~m} \mathrm{x} 1.2 \mathrm{~m} \times 0.2 \mathrm{~m}$ slabs were prepared, with two being singly reinforced and two doubly reinforced. A sample of the slabs is shown in Fig.3. In addition, samples were prepared for mechanical properties evaluation, rapid chloride penetration testing (RCPT), and SEM samples preparation. The mechanical evaluation included compressive, split tensile, flexural strength and modulus of elasticity.

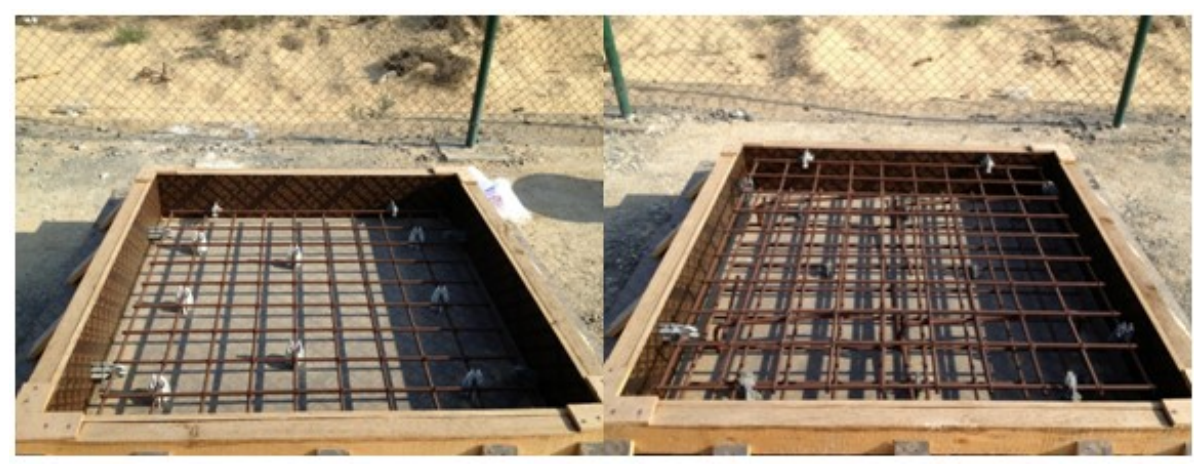

a) Singly reinforced slab

b) Doubly reinforced slab

Fig. 3.specimens details

\subsection{Project Stages:}

\subsubsection{Stage I-Development and evaluation - Laboratory production:}

The mix development of the LWC was based on a normal weight self-consolidated concrete mix[33]. This mix has been developed for more than a year, and it showed adequate consistency and repeatability. Normal weight fine aggregates used in this stage were crushed fine aggregates as indicated in Table5(S.G $=2.58$, $4.75 \mathrm{~mm}$ maximum size), as well as dune sand ( $\mathrm{S} . \mathrm{G}=2.56,0.6 \mathrm{~mm}$ maximum size). The combined lightweight aggregates with normal weight fine aggregates sieve analysis according to ASTM C 330M-2009 is shown in Table6.

Table 6. Sieve analysis of coarse lightweight aggregates combined with normal weight fine aggregates

\begin{tabular}{|l|l|l|l|l|l|l|l|l|l|}
\cline { 2 - 9 } \multicolumn{1}{c|}{} & \multicolumn{7}{|c|}{ ASTM C 330M-2009 Limits (Combined coarse and fine aggregate, 9.5-0 mm) } \\
\cline { 2 - 10 } \multicolumn{1}{c|}{ Grading requirement } & - & 100 & $100-90$ & $90-65$ & $65-35$ & - & $25-10$ & $15-5$ & $10-0$ \\
\hline LYTAG & 100 & $100(\mathrm{Y})^{*}$ & $100(\mathrm{Y})$ & $59.7(\mathrm{~N})$ & $56.1(\mathrm{~N})$ & 47.9 & $33.1(\mathrm{~N})$ & $12.5(\mathrm{Y})$ & $1.4(\mathrm{Y})$ \\
\hline
\end{tabular}

*() Meets requirement (Y), does not meet requirement (N)

Commonly, lightweight concrete would not achieve the desired characteristics if the lightweight aggregates used were not pre-wet or pre-soaked to overcome the absorption capacity[34, 35]. The aggregates were pre-wet by adding water equal to $15 \%$ of the lightweight aggregate weight, as specified by the manufacturer of the LWA[26].

\subsubsection{Stage II - Field application:}

There was a change in the fine aggregate used, due to unavailability of the required fine aggregates at the ready mix plant. Normal weight fine aggregates used in this stagewere beach washed sand as shown in Table5, having 2.58 specific gravity, as well as dune sand having specific gravity of 2.56 . According to the concrete batch plant, the LWT aggregates werenot pre-wet during storage, for the plant was not equipped with special sprinklers. Thus, pre-wetting water was added during mixing as an alternative. The water amount added was equal to $5 \%$ of the lightweight aggregate weight. This amount was selected to barely provide sufficient water for the aggregates to absorb, avoiding remarkable alteration of the mixing water. In addition, $61 \mathrm{~kg}$ of ice were added to the $2 \mathrm{~m}^{3}$ mix to lower the concrete temperature, which was poured at an ambient temperature of $35{ }^{\circ} \mathrm{C}$, noon time. The truck arrived to the outdoor testing facility 1 hour after batching. The results of the field application are presented in the following section. Table 7summarizes the changes that occurred throughout the transition from the laboratory development to the field implementation. 
Table 7. Summary of changes in project stages

\begin{tabular}{|l|l|l|}
\hline Parameter & Stage I & Stage II \\
\hline Fine Aggregates Used & Crushed sand + Dune Sand & $\begin{array}{l}\text { Washed Beach Sand + Dune } \\
\text { Sand }\end{array}$ \\
\hline Ice Addition & No Addition & $30.5 \mathrm{~kg} / \mathrm{m}^{3}$ \\
\hline Pre-wetting Method & $\begin{array}{l}15 \% \text { of aggregate weight } \\
\text { added as water to the } \\
\text { aggregates } 30 \text { minutes prior } \\
\text { to mixing }\end{array}$ & $\begin{array}{l}5 \% \text { of aggregate weight was } \\
\text { added as water to the mixer }\end{array}$ \\
\hline
\end{tabular}

\subsection{Lab Mix (Mix\#1):}

\section{Results}

\subsubsection{Flowability and unit weight}

The mix achieved $500 \mathrm{~mm}$ flowability in less than 40 seconds, complying with self-consolidated concrete requirements [36], as shown in Fig. 4. There was no segregation encountered in the mix. The equilibrium unit weight was in the range of 1900-1920 kg/m³, according to ASTM 567/567M-2011 [37].

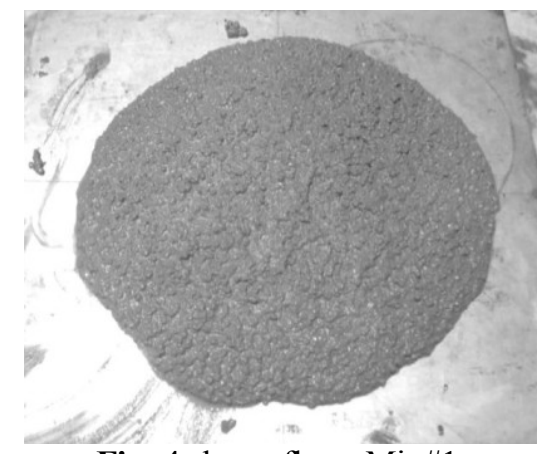

Fig. 4.slump flow- Mix\#1

\subsubsection{Mechanical properties}

Fig. 5 shows the strength development of Mix\#1, the compressive strength reached $46.1 \mathrm{MPa}$ at 28 day, meeting the high strength requirements of structural lightweight concrete [35]. The failure mode of the crushed concrete specimens was observed. Fig. 6a shows the failure mode of Mix\#1. Vertical crushing failure was the predominant failure mode illustrating good bonding between aggregates and cement paste. The modulus of elasticity of was $23.6 \mathrm{GPa}$, while flexural strength using the three point loading test was found to be $2.1 \mathrm{MPa}$, which is considered low flexural strength, when compared with the lower limits of the ACI-318 modulus of rupture prediction equation for sand lightweight concrete $\left(0.62 \lambda \sqrt{f_{c}}{ }^{\prime}\right)$ which is $3.6 \mathrm{MPa}[38]$.Generally, rupture moduli of normal weight concrete comply with the ACI equation.

\subsection{Field Implementation Casting (Mix\#2) \\ 4.2.1 Flowability and unit weight}

Mix\#2 was casted in site as shown in Fig. 7. Although the mix achieved high flowability $(700 \mathrm{~mm}$ in 30 seconds), as shown in Fig. 8, the aggregate floated to the surface, indicating noticeable segregation. The main reason for segregation was the low viscosity of the mix, which can be attributed to the following reasons: firstly, the replacement of crushed with beach washed sand. Crushed sand can be used as a filling material,while maintaining the viscosity of the mix, which is a crucial element in self-consolidated concrete mixes. Beach washed sand, which is finer than crushed sand, has lower mechanical friction, leading to increased flowability of the mix due to the viscosity drop. Secondly, replacing pre-wetting by adding water to the mix might have influenced the effective mixing water, in addition to molten ice. The equilibrium unit weight was found to be $\sim 1800 \mathrm{~kg} / \mathrm{m}^{3}$, satisfying LWC weight requirements [35]. 


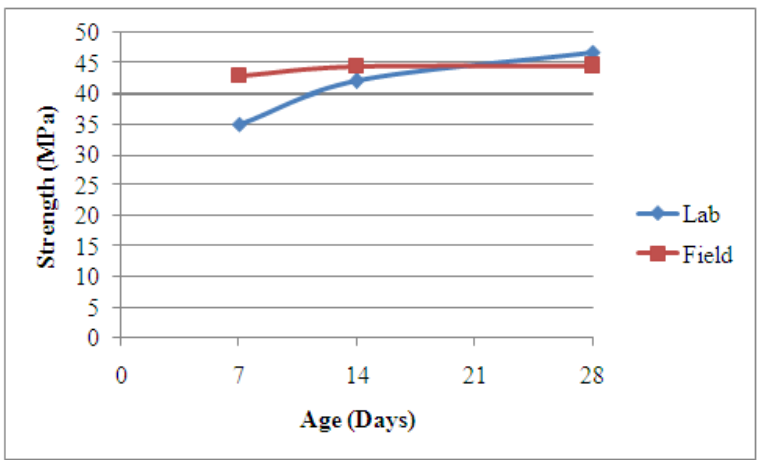

Fig. 5.strength development of Mix \#1 and Mix\# 3

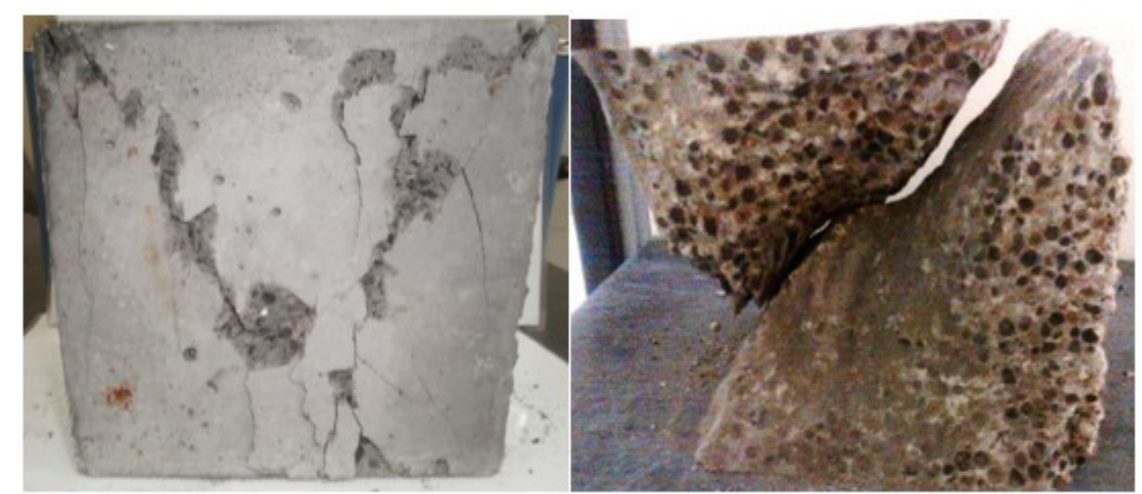

a) Mix\#1 (Vertical Crushing)

b) Mix\#2 (Vertical Crushing + Shear)

Fig. 6.failure modes of laboratory and field casted samples - compression test

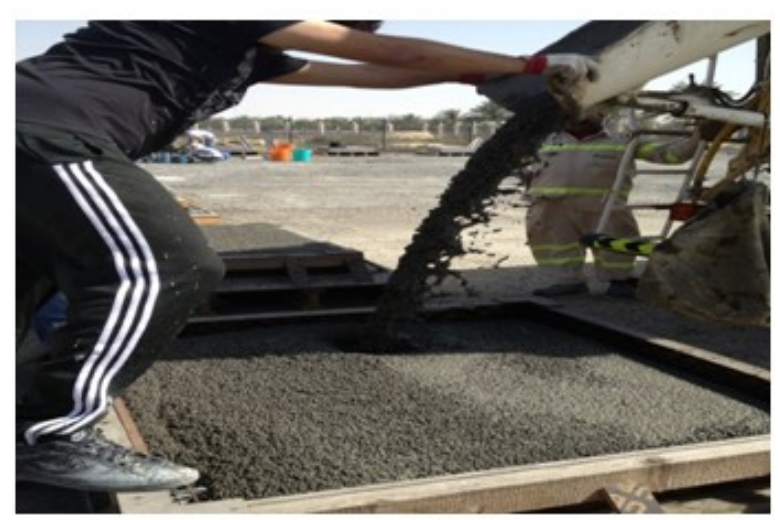

Fig. 7.concrete casting in-situ

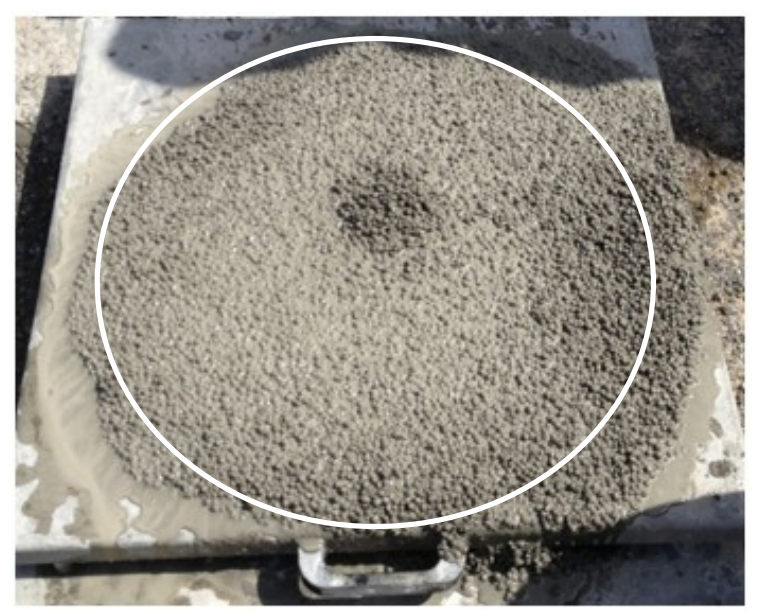

Fig. 8.slump flow - field application. 


\subsubsection{Mechanical Properties}

The strength development of Mix\#2 is shown in Fig. 5.It can be observed that the pattern of the strength development is similar, except for the early strength gain at which Mix\#2 exhibited steeper strength gain. Although segregation occurred in Mix\#2, it is believed that it has not affected strength since the 28-day strengths are comparable; reaching 46.8 MPa and 44.6 MPa for Mixes \#1 and \#2, respectively. Fig.6b shows the failure mode of Mix\#2. Shear failure accompanied crushing in Mix\#2 specimens. This is due to the reduced bonding of constituents, caused by segregation.

Modulus of elasticity of Mix\#2 was 17.2 GPa. Mix\#2 is expected to suffer higher deformations than Mix\#1, which triggers other durability related issues, such as creep and thermal expansion in restrained structural elements. Nonetheless, elasticity values for Mix\#1 and Mix\#2 are within the typical range of elasticity modulus for lightweight concrete[39].Mix\#2 achieved flexural strength of 1.6 MPa, indicating low tensile load resistance. Such low tensile load resistance is attributed to the weak tensile resistance of the aggregates in both mixes, with a pronounced effect of aggregate floatation, on the flexural strength as well on Mix\#2 as shown in Fig.9.

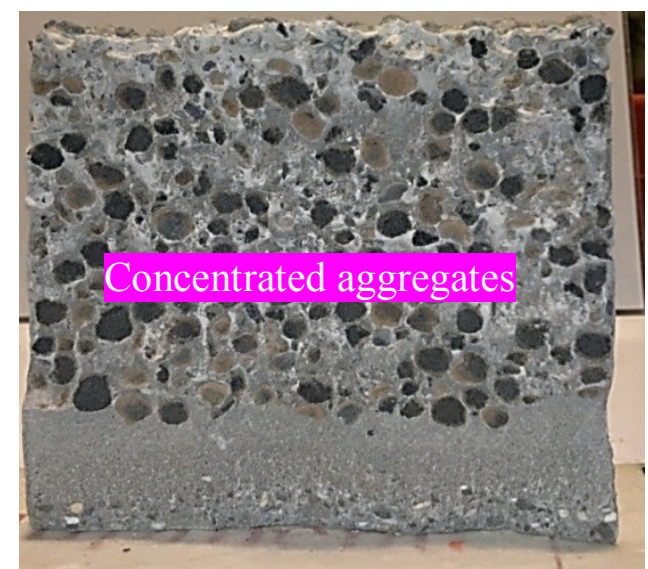

Fig. 9.illustration of segregation along concrete cross section.

\subsection{Aggregate Distribution Evaluation:}

\section{Discussion:}

In order to investigate the aggregate distribution, $3.75 \mathrm{~cm}(1.5 ")$ samples were saw-cut from a concrete cube along the specimen height as shown in Fig. 10 for Mix\#1 and Mix\#2. The bottom and top cross-sections were examined to determine any changes of aggregate distribution. Moreover, middle cross-sections were checked to ensure that there are no sudden changes in the distribution. Both mixes had minimal or no compaction, as they are designed to be self-compacting. It is clear that aggregates are well distributed along the depth of the specimen in Mix\#1, indicating adequate static stability of the mix. On the contrary, Mix\#2 displayed clear segregation, observed by the lack of aggregates in the lowest cross-section image (starting at 4.5 " from top surface) as shown in (e and f). This is not only due to the floatation of the lightweight aggregates particles because of low specific gravity, but also due to the low resisting force, which is viscosity of the cement paste. The cement paste viscosity was altered from lab conditions due the change of friction between fine aggregates particles, introduced by changing it from crushed sand to beach washed sand. Moreover, it is overly challenging to estimate the effective water content at the time of pouring, with several other variables contributing to the problem; molten ice volume, travel time, and truck mixer rotation power.

\subsection{Durability Requirements}

5.2.1 RCPT

There are various durability features that concrete is required to possess; chloride ion penetration resistance is among such features. Chloride attack can accelerate deterioration of concrete[28], especially in coastal developments where there is a high percentage of air-bourne chloride. Moreover, ACI 318 has adopted limiting $\mathrm{w} / \mathrm{c}$ to 0.4 to improve resistance to ion chloride penetration. Resistance to chloride ion penetration of concrete depends on both the cement paste and aggregate. In general, the denser the mix, the less permeable concrete is [15]. ASTM C-1202 suggests testing the resistance to chloride ion penetration in an accelerated manner, through exposing concrete specimens in a galvanic cell set-up as further discussed in the standard.

Although this test might overestimate the exposure, it provides reasonably accurate results that can help implement remedial or repair decisions for real life structures. In this study, concrete specimens were cured for 3 days and left to air-dry for 90 days. The $50 \mathrm{~mm}$ thick specimens needed for the RCP tests were extracted from 
the middle of the $20 \mathrm{~cm} \times 10 \mathrm{~cm}$ (diameter) casted concrete samples, to ensure direct comparability.Mix\#1 passed 635 coulombs only, with very low penetration potential [40]. As for Mix \#2,aggregate floatation has significantly affected the rapid chloride penetration resistance of concrete in this study. Results of the RCPT performed at 90 days showed that 4262 coulombs have passed through Mix\#2, indicating high potential chloride ion permeability according to ASTM C-1202, compared to the lab prepared mix. The poor aggregate distribution through the depth of concrete, along which samples were cored, can adversely affect the chloride penetration resistance of concrete. Segregated Mix \#2 had a high percentage of non-resistant highly-porous cement paste compared to lightweight aggregate (LWA). In general, LWA helps reduce the chloride ion permeability by acting like a reservoir for the ions, mitigating passage of charges [30]. Such high permeability is an alarming matter for cast-in-place concrete.

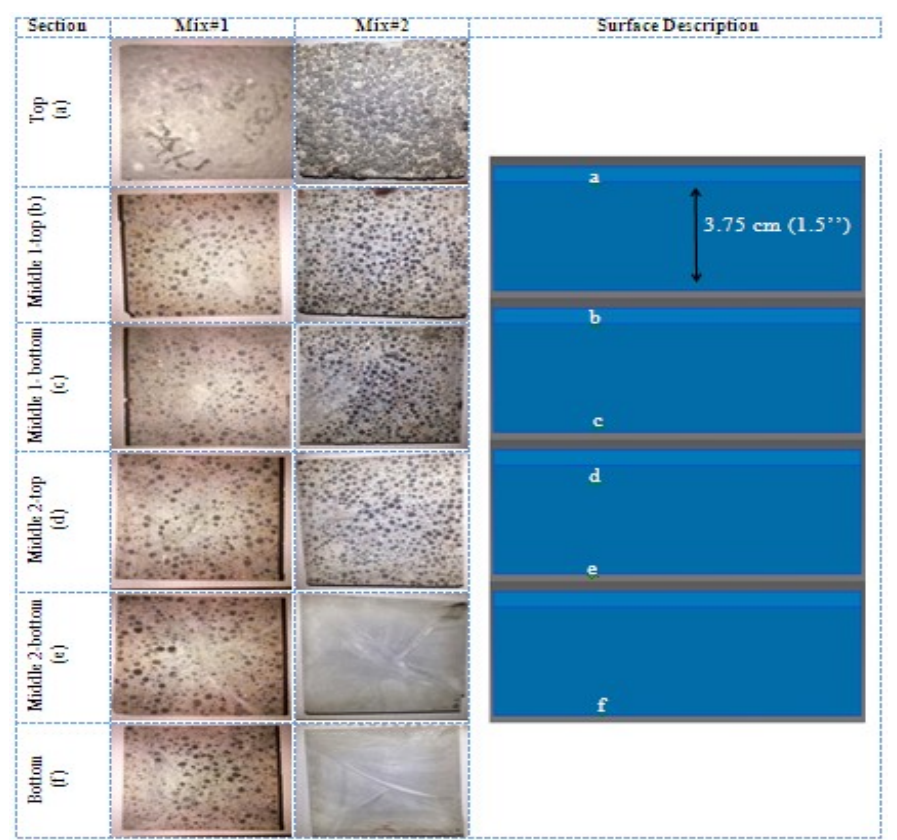

Fig. 10.cross-section investigation along depth of specimens for Mix\#1 and Mix\#2

\subsubsection{SEM}

Inspection of Lightweight Concrete (LWC) microstructural features is crucial, since the Interfacial Transition Zone contributes to the overall behavior, along with cement paste and aggregate strength. Concrete samples were extracted to examine the microstructural features of the LWC prepared for this research project. Fig. 11a shows the SEM scan for Mix\#1, and it is illustrated that there is a distinct layer surrounding the aggregate in the area bound by the two dashed lines. The phenomenon at which distinct layers surround the aggregates is commonly referred to as the wall effect [13]. Mix\#1 had no extra water sources such as molten ice, except for the initial pre-wetting to overcome absorption. However, the aggregates have a higher absorption capacity as mentioned in the materials description (30.7\%). Therefore, aggregates absorbed more water into the shell of the aggregate, lowering the effective $\mathrm{w} / \mathrm{b}$ locally around the aggregate, which led to the formation porous cement paste surrounding the aggregate particles. Mix\#2 did not exhibit formation of the wall effect. It is believed that this is due to the extra water from molten ice in addition to the water added to the mix as an alternative to pre-wetting, providing enough water content for the aggregates to become fully saturated. Nevertheless, no constricted mechanical interlock was observed in Mix\#2 as shown in Fig. 11b. Moreover, the existence of large pores $(\sim 1 \mathrm{~mm}$ diameter) further explains the high potential for chloride ion penetration from the RCPT results, which again reflects the negative implications of aggregate floatation.

\subsection{Lessons Learned and Observations}

By inspecting the failed concrete samples, it can be deduced that there was good bonding between cement paste and aggregate particles. This is supported by the fact that the plane of failure passes through the aggregate rather than the separation of aggregates from the paste. Such bond is attributed to the surface texture of the aggregate. Table8presents a summary of the laboratory-prepared mix and the cast-in-place mix. 


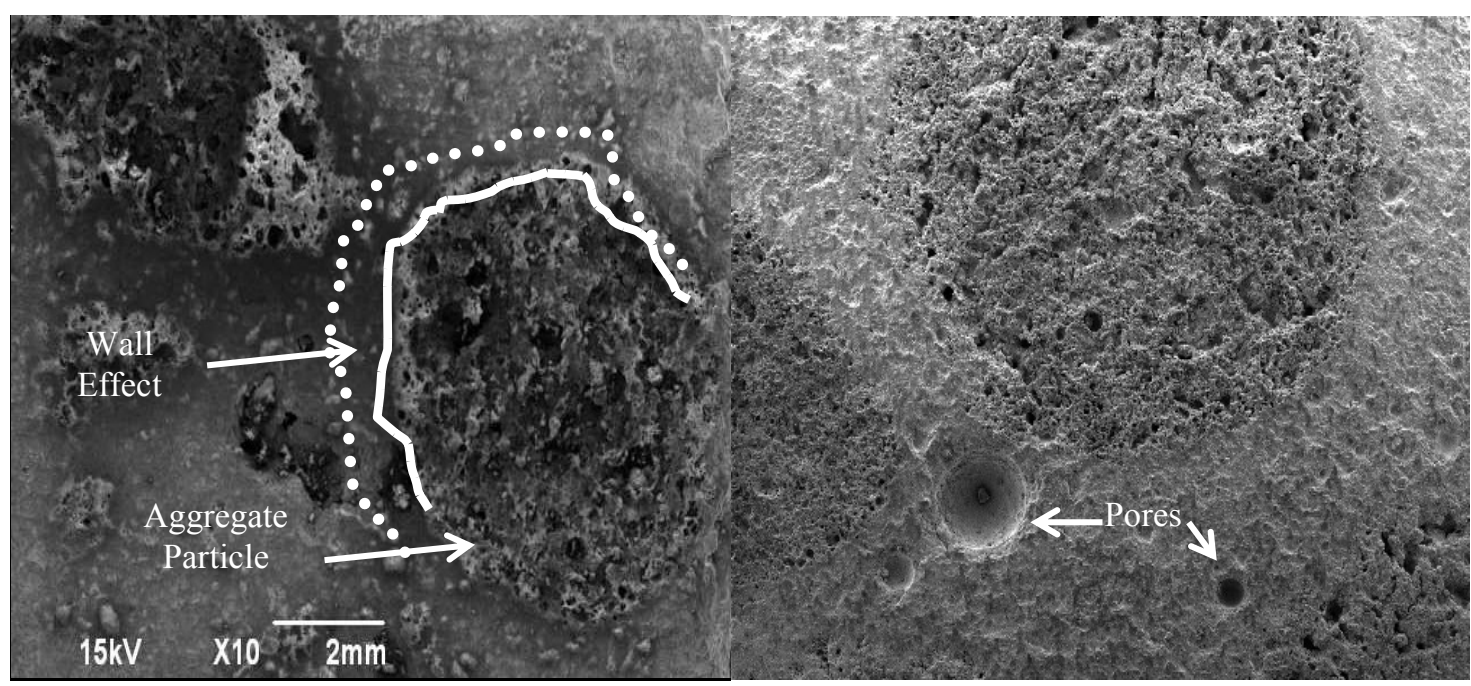

a) Mix\#1 microstructure

b) Mix\#2 microstructure

Fig. 10. SEM scans of Mix\#1 and Mix\#2.

\subsubsection{Comparison of properties with ACI-318 code provisions}

ACI 318 equations based on $\sqrt{f_{c}}$, (cylinder strength) were used for evaluating mechanical properties of both mixes, to verify adequate performance from a design prospective. Since the specimens used for testing compressive strength in this study were cubes, a reduction factor was used in order to use the equations. A recent study carried out by [41] in an effort to quantify the effect of size and shape of specimens on compressive strength resulted in a reduction factor of 0.93 . However, the authors decided to adopt a range of $0.8-0.9$ to predict equivalent cylinder compressive strength, hence, cover expected variability of results. Table 9 shows the comparison between actual results of the experimental program against ACI prediction equations for Mix\#1 and Mix\#2. As shown in Table 9, Mix\#1 achieved comparable modulus of elasticity ( $2 \%-7 \%$ lower) to the predicted value, whereas Mix\#2 was 14\%-21\% lower than the predicted value. Mix\#2, as a result, is expected to suffer higher creep strains and higher deformability under applied load. Furthermore, both mixes achieved rupture modulus (40\%-50\%) lower than predicted values. Nevertheless, the ACI-318 equation for predicting rupture modulus is generally said to overestimate the rupture modulus [42]. Moreover, since Mix\#2 achieved equilibrium unit weight of $1800 \mathrm{Kg} / \mathrm{m}^{3}\left(<1840 \mathrm{Kg} / \mathrm{m}^{3}\right)$, the application of this mixture without assessing its unit weight can involve under designing some structural elements, one-way slabs for instance, as summarized in Table 4. Thus, unit weight, in addition to strength, is to be carefully examined during actual construction/design.

Table 8. Field application vs. laboratory development evaluation summary

\begin{tabular}{|l|l|l|}
\hline Feature & Mix\#1 & Mix\#2 \\
\hline Pre-wetting & $\begin{array}{l}15 \% \text { of aggregate weight added } \\
\text { as water to the aggregates 30 } \\
\text { minutes prior to mixing }\end{array}$ & $\begin{array}{l}\text { 5\% of aggregate weight was } \\
\text { added as water to the mixer }\end{array}$ \\
\hline Filler Material Used & Crushed sand + Dune Sand & $\begin{array}{l}\text { Washed Beach Sand + Dune } \\
\text { Sand }\end{array}$ \\
\hline Ice Addition & No addition & $30.5 \mathrm{~kg} / \mathrm{m}^{3}$ \\
\hline Slump Flow $(\mathrm{mm})$ & 500 & 700 \\
\hline Static Stability & No Segregation & Segregated \\
\hline Unit Weight $\left(\mathrm{Kg} / \mathrm{m}^{3}\right)$ & 1900 & 1800 \\
\hline$f^{\prime}$ c $(\mathrm{MPa})$ & 46.8 & 44.6 \\
\hline f'r $(\mathrm{MPa})^{\mathrm{E}(\mathrm{GPa})}$ & 2.1 & 1.6 \\
\hline RCPT $(\mathrm{Coulombs})$ & 23.6 & 17.2 \\
\hline Microstructure & 635 (Very low) & 4262 (High) \\
\hline & $\begin{array}{l}\text { Distinct layer surrounding the } \\
\text { aggregate (Wall effect) }\end{array}$ & $\begin{array}{l}\text { No wall effect, but no evidence } \\
\text { of mechanical interlock }\end{array}$ \\
\hline
\end{tabular}

Table 9.Comparison of Mechanical Properties of Mix\#1 and Mix\#2 with ACI Predictions

\begin{tabular}{|c|c|c|c|c|c|c|}
\hline & \multirow{2}{*}{$\mathbf{f}_{\mathrm{c}}{ }^{*}{ }^{\prime}(\mathrm{MPa})$} & \multirow{2}{*}{$\begin{array}{c}\text { Unit Weight } \\
\left(\mathrm{Kg} / \mathrm{m}^{3}\right)\end{array}$} & \multicolumn{2}{|c|}{ E (GPa) } & \multicolumn{2}{|c|}{$\mathbf{f}_{\mathrm{r}}^{\prime}(\mathbf{M P a})$} \\
\hline & & & Actual & Predicted** & Actual & Predicted $* * *$ \\
\hline Mix\#1 & $37.4-42.4$ & 1900 & 23.6 & $21.8-23.1$ & 2.1 & $3.22-3.42$ \\
\hline Mix\#2 & $35.7-40.1$ & 1800 & 17.2 & $19.6-20.8$ & 1.6 & $3.15-3.34$ \\
\hline
\end{tabular}

$*$ Converted cylinder compressive strength $* *$ Based on $\mathrm{E}_{\mathrm{c}}=0.043 \mathrm{w}_{\mathrm{c}}^{1.5} \sqrt{\mathrm{f}_{\mathrm{c}}^{\prime}}$ in SI units

$* * *$ Based on $\mathrm{f}_{\mathrm{r}}=0.62 \lambda \sqrt{\mathrm{f}_{\mathrm{c}}^{\prime}}$ in SI units, $\lambda=0.85$ for sand-lightweight 
From the results of the investigation, it can be concluded that not always field application of laboratory developed mixes will reflect mixes' potential. This can undesirably discourage the adoption of such mixes in real-life construction application.Such negative perception of newly developed mixes can be due to reasons such as unavailability of required materials leading to mix adjustments or even improper pre-wetting alternatives. Moreover, the RCPT results along with SEM images prove that the quality control measures commonly followed in the industry are not adequate. The common practice is to check workability, temperature, and air content, in addition to 7-days compressive strength. Another important feature related to lightweight structural application is the time dependent response. Shrinkage and creep were not evaluated in this research project. Yet, it is required to develop a clear understanding of the shrinkage and creep behavior of self-consolidated lightweight concrete. This is the case because lightweight concrete and self-consolidated concrete have different shrinkage and creep responses. In addition, factors affecting shrinkage and creep of each individual mix might change the response of a self-consolidated lightweight concrete mix.

Lessons learned from this experience are that there should be strict control over mixes in construction sites, especially in the case of lightweight concrete, for absorption can be a determinant factor in the overall process. Moreover, additional work is required to resolve lightweight concrete casting problems occurring on site, since remedial measures carried out for conventional concrete might not be optimal. Thus, slight variations that occur during concrete production similar to that discussed in the study can lead to completely different performance and uniformity of concrete. Hence, different concrete would exhibit dissimilar properties, which most probably would not conform to ACI-318 requirements for structural design shown in Table 4. Such variations along with the potential of impairing durability dictate the need for additional evaluation of in-situ practices regarding handling, production, and development of HSSCLWC.

\section{Concluding Remarks}

In this paper, the field application of a high strength self-consolidated lightweight concrete mix and the impact of their preparation on strength and durability was presented. This research effort was carried out to link the gap between laboratory and field application, and to provide an assessment for LWC mass production. The results from the cast-in-place mix were compared to that of the laboratory mix. From the work presented, the following was concluded:

- The lab prepared mix and the cast-in-place mix had comparable compressive strength (46.8 MPa and 44.6 $\mathrm{MPa}$ ) respectively. Results of the RCPT showed that the cast-in-place mix was classified in the high permeability class according to ASTM C-1202, indicating potential for deterioration

- The difference in mixing practices and preparation procedures between laboratories and mixing plants can greatly affect the fresh and hardened concrete properties. This can distort the laboratory optimized results and discourage the application of lightweight concrete.

- Although structural elements designed based on similar $f_{c}^{\prime}$ and having the same structural detailing (reinforcement, spacing, etc...), the structural response might be different due to difference in durability performance and microstructural features.

- Effective mixing water during the time travelled by concrete trucks should be carefully controlled. The water content at any point in time of the truck travel should be modeled to govern the w/b not to increase excessively or cause segregation.

\section{Acknowledgement}

This research effort is a part of the American University of Sharjah's Provost's Challenge Grant, 2011. The financial support provided by the Office of Research and Graduate Studies at the American University of Sharjah is greatly appreciated.

\section{References}

[1]. F. S. Barbosa, M. C. R. Farage, A.-L. Beaucour, and S. Ortola, Evaluation of aggregate gradation in lightweight concrete via image processing, Construction and Building Materials,29(4), 2012, 7-11.

[2]. N. U. Kockal and T. Ozturan, Effects of lightweight fly ash aggregate properties on the behavior of lightweight concretes, Journal of Hazardous Materials, 179(1-3), 2010, 954-965.

[3]. R. Polat, R. Demirboğa, M. B. Karakoç, and İ. Türkmen, The influence of lightweight aggregate on the physico-mechanical properties of concrete exposed to freeze-thaw cycles, Cold Regions Science and Technology, 60(1),2010,51-56.

[4]. H. Y. Wang, Study on durability of densified high-performance lightweight aggregate concrete, Computers and Concrete, 4(6), 2007, 499-510.

[5]. H. Y. Wang, Durability of self-consolidating lightweight aggregate concrete using dredged silt, Construction and Building Materials, 23(6),2009, 2332-2337. 
[6]. S. Yehia, M. AlHamaydeh, and S. Farrag, High strength lightweight SCC matrix with partial normal weight coarse aggregate replacement: strength and durability evaluations, ASCE Journal of Materials in Civil Engineering,http://ascelibrary.org/doi/abs/10.1061/(ASCE)MT.1943-5533.0000990,2014.

[7]. N. U. Kockal and T. Ozturan, "Durability of lightweight concretes with lightweight fly ash aggregates, Construction and Building Materials, 25(3), 2011,1430-1438.

[8]. H. Z. Cui, T. Y. Lo, S. A. Memon, and W. Xu, Effect of lightweight aggregates on the mechanical properties and brittleness of lightweight aggregate concrete, Construction and Building Materials, 35(10),2012149-158.

[9]. S.-D. Hwang, K. H. Khayat, and O. Bonneau, Performance-based specifications of self-consolidating concrete used in structural applications, ACI materials journal, 103(2), 2006, 121-129.

[10]. M. Nehdi, Only tall things cast shadows: opportunities, challenges and research needs of self-consolidating concrete in super-tall buildings, Construction and Building Materials, 48(11),2013, 80-90.

[11]. D. Moreno, F. Zunino, Á. Paul, and M. Lopez High strength lightweight concrete (HSLC): challenges when moving from the laboratory to the field, Construction and Building Materials, 56(4), 2014, 44-52.

[12]. R. Henkensiefken, D. Bentz, T. Nantung, and J. Weiss, Volume change and cracking in internally cured mixtures made with saturated lightweight aggregate under sealed and unsealed conditions, Cement and Concrete Composites, 31(7), 2009, 427-437.

[13]. I. Topcu and T. Uygunoğlu, Effect of aggregate type on properties of hardened self-consolidating lightweight concrete (SCLC),Construction and Building Materials, 24(7), 2010, 1286-1295.

[14]. J. Lindgård, Ö. Andiç-Çakır, I. Fernandes, T. F.Rønning, and M. D. A. Thomas, Alkali-silica reactions (ASR): literature review on parameters influencing laboratory performance testing, Cementand Concrete Research, 42(2), 2012, 223-243.

[15]. A. M. Neville, Properties of concrete, 4th Ed. (New York, USA: John Wiley \& Sons Inc., 1996).

[16]. M. S. Ashtiani, A. Scott, and R. Dhakal, Mechanical and fresh properties of high-strength self-compacting concrete containing class C fly ash, Construction and Building Materials, 47(10),2013, 1217-1224

[17]. M. Beygi, M. Kazemi, I. Nibin, and A. Vesghi, Javad, The effect of water to cement ratio on fracture parameters and brittleness of self-compacting concrete, Materials\& Design, 50(9), 2013,267-276,

[18]. M. C. Torrijos, B. E. Barragan, and R. L. Zerbino, Physical-mechanical properties, and mesostructure of plain and fibre reinforced self-compacting concrete, Construction and Building Materials, 22(8), 2008, 1780-1788,

[19]. P. Dinakar, K. G. Babu, and M. Santhanam, Durability properties of high volume fly ash self-compacting concretes, Cement and Concrete Composites, 30(10), 2008, 880-886.

[20]. B. Felekoglu and H. Sarikahya, Effect of chemical structure of polycarboxylate-based superplasticizers on workability retention of self-compacting concrete, Construction and Building Materials, 22(9),2008, 1972-1980.

[21]. B. Sukumar, K. Nagamani, and R. Raghavan, Evaluation of strength at early ages of self-compacting concrete with high volume fly ash, Construction and Building Materials, 22(7), 2008,1394-1401.

[22]. H. Yazici, The effect of silica fume and high-volume Class $\mathrm{C}$ fly ash on mechanical properties, chloride penetration and freezethaw resistance of self-compacting concrete, Construction and Building Materials, 22(4), 2008, 456-462.

[23]. A. Lotfy, Lightweight self-consolidating concrete: statistical modelling, mixture design and performance evaluation, doctoral diss., Reyerson University, Canada, 2012.

[24]. B. Chen and J. Liu, Contribution of hybrid fibers on the properties of the high-strength lightweight concrete having good workability, Cement and Concrete Research35(5), 2005, 913-917.

[25]. C.-L. Hwang and M.-F. Hung, Durability design and performance of self-consolidating lightweight concrete, Construction and Building Materials, 19(8), 2005, 619-626.

[26]. LYTAG, Design Guidance for LYTAG LWC, www.lytag.net,. North Yorkshire, UK, 2009, 16.

[27]. ESCSI, Back-up statistics to building bridges and marine structures with structural lightweight aggregate concrete, Expanded Shale, Clay, and Slate Institute, 2001.

[28]. A. Durán-Herrera, P.-C. Aitcin, and N. Petrov, Effect of saturated lightweight sand substitution on shrinkage in $0.35 \mathrm{w} / \mathrm{b}$ concrete, ACI Materials Journal, 104(1),2007, 48-52.

[29]. ASTMC330/330M, Standard specifications for lightweight aggregates for structural applications, (West Conshohocken, PA: ASTM International, 2009).

[30]. M. N. Haque, H. Al-Khaiat, and O. Kayali, Strength and durability of lightweight concrete, Cement and Concrete Composites, 26(4), 2004, 307-314.

[31]. H. Z. Cui, T. Y. Lo, S. A. Memon, and W. Xu, Effect of lightweight aggregates on the mechanical properties and brittleness of lightweight aggregate concrete, Construction and Building Materials, 35(2), 2012, 149-158.

[32]. T. Y. Lo, W. C. Tang, and H. Z. Cui, The effects of aggregate properties on lightweight concrete, Building and Environment, 42(8),2007, 3025-3029.

[33]. S. Yehia, O. Abudayyeh, B. Bhusan, M. Maurovich, and A. Zalt, Self-consolidating concrete mixture with local materials: proportioning and evaluation, Materials Science Research Journal, 3(1-2), 2009, 41-64.

[34]. N. Kabay and F. Aköz, Effect of prewetting methods on some fresh and hardened properties of concrete with pumice aggregate, Cement and Concrete Composites, 34(4), 2012, 503-507.

[35]. ACI 213, Guide for structural lightweight concrete,(Farmington Hills, Mich.: American Concrete Institute, 2003).

[36]. ACI 237, Self-consolidating concrete. (Farmington Hills, Mich: American Concrete Institute, 2007).

[37]. ASTMC567/C567M, standard test method for determining density of structural lightweight concrete, (West Conshohocken, PA: ASTM International, 2011).

[38]. ACI 318, Building code requirements for structural concrete and commentary, (Farmington Hills, Mich.: American Concrete Institute, 2011).

[39]. F. P. Zhou, B. I. G. Barr, and F. D. Lydon, Effect of coarse aggregate on elastic modulus and compressive strength of high performance concrete, Cement and Concrete Research,25(1), 1995, 177-186.

[40]. ASTM C1202, Standard test method for electrical indication of concrete's ability to resist chloride ion penetration,(West Conshohocken, PA: ASTM International, 2012).

[41]. J.-I. Sima, K.-H. Yang, H.-Y. Kim, and B.-J. Choi, Size and shape effects on compressive strength of lightweight concrete, Construction and Building Materials, 38(1), 2013, 854-864.

[42]. A. Vilanova, J. Fernández-Gómez, and G. A. Landsberger, Mechanical Properties of Self-Consolidating Concrete Using Conventional Concrete Models, ACI Materials Journal, 109(6), 2012, 587-596. 